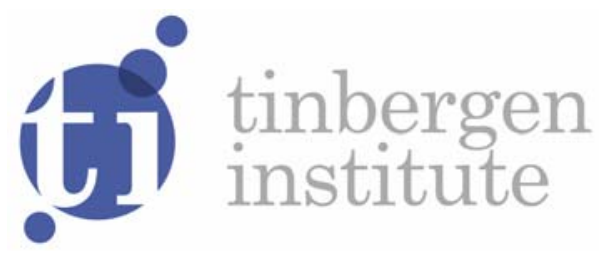

\title{
Firm-Specific Information and Explicit Collusion in Experimental Oligopolies
}

Francisco Gomez-Martin

Sander Onderstal

Joep Sonnemans 
Tinbergen Institute is the graduate school and research institute in economics of Erasmus University Rotterdam, the University of Amsterdam and VU University Amsterdam.

More TI discussion papers can be downloaded at http://www.tinbergen.nl

Tinbergen Institute has two locations:

Tinbergen Institute Amsterdam

Gustav Mahlerplein 117

1082 MS Amsterdam

The Netherlands

Tel.: +31(0)205251600

Tinbergen Institute Rotterdam

Burg. Oudlaan 50

3062 PA Rotterdam

The Netherlands

Tel.: +31(0)10 4088900

Fax: $+31(0) 104089031$

Duisenberg school of finance is a collaboration of the Dutch financial sector and universities, with the ambition to support innovative research and offer top quality academic education in core areas of finance.

DSF research papers can be downloaded at: http://www.dsf.nl/

Duisenberg school of finance

Gustav Mahlerplein 117

1082 MS Amsterdam

The Netherlands

Tel.: +31(0)20 5258579 


\title{
Firm-specific information and explicit collusion in experimental oligopolies
}

\author{
Francisco Gomez-Martinez, Sander Onderstal, and Joep Sonnemans *
}

May 10, 2015

\begin{abstract}
We experimentally study the effect of information about competitors' actions on cartel stability and firms' incentives to form cartels in Cournot markets. As in previous experiments, markets become very competitive when individualized information is available and participants cannot communicate. In contrast, when communication is possible, results reverse: Markets become less competitive and cartels become more stable when individualized information is available. We also observe that the extra profits that firms obtain thanks to the possibility to communicate are higher when individualized information is present, suggesting that firms have greater incentives to form cartels in that situation.
\end{abstract}

Keywords: Cournot oligopoly; Cartels; Information; Experiments JEL classification: C92; L13; L41

Acknowledgments: The authors are grateful to Maria Bigoni, David Cooper, David Kopanyi, Anita Kopanyi-Peuker, Hans-Theo Normann, Jan Potters, Chris Snyder, and participants in the IIOC meeting in Boston, the Tinbergen Institute lunch seminar, and the ABEE conference in Amsterdam for helpful comments. We also thank the financial support from the University of Amsterdam Research Priority Area in Behavioral Economics.

* University of Amsterdam (CREED/FEB/ASE), and Tinbergen Institute, Roetersstraat 11, 1018 WB Amsterdam. F.GomezMartinez@uva.nl; Onderstal@uva.nl; JoepSonnemans@gmail.com. 


\section{Introduction}

What is the impact of publishing firm-specific data on competition in oligopolistic markets? This question has been subject to a lively debate in the economics literature. The debate goes at least back to Stigler's (1964) work. Stigler argues that market transparency facilitates collusion because firms are better able to monitor other firms deviating from a collusive agreement so that deviations can be punished more effectively. ${ }^{1}$ Stigler's reasoning found fertile ground in the literature and can still be found in modern industrial organization textbooks. However, in the late 1990s, new theoretical insights saw the light that would cast doubt on the universality of Stigler's results. In particular, Vega-Redondo (1997) analyzes imitation learning and bounded rationality in homogeneous Cournot markets and derives the exact opposite result than Stigler's: Full disclosure of individual data makes Cournot markets more competitive, not less, when firms imitate the most profitable firm. ${ }^{2}$

The empirical literature has not settled the debate. Albaek et al. (1997) find support for Stigler's argument by observing a 15-20\% increase in prices within one year following the Danish antitrust authority's decision to publish firms' prices in the ready-mixed concrete market. In contrast, laboratory results are more in line with Vega-Redondo's results. Laboratory markets tend to become more competitive when information about individual profits, quantities and prices is available than when only aggregate information is available (Huck et al., 1999, 2000, Offerman et al., 2002, and Altavilla et al., 2006). ${ }^{3}$ Imitation seems to be an important driving force: When individualized information about conduct and profits of competitors is available, participants tend to mimic the most successful firm, which is typically the firm producing the largest quantity. 4

The question of the impact of publishing firm-specific data on competition is not only of academic interest. In December 1986, the European Commission decided in the Fatty Acids case that information sharing between Unilever, Henkel, and Oleofina violated Article 85(1) of the Treaty of Rome (now Article 101(1)). ${ }^{5}$ Kühn (2001) argues more in general that "[i]ndividualized information exchange about past prices and quantities should [...] be considered an anti-competitive agreement in the sense of Art. 81(1) [now Art. 101(1)]." In contrast, regulators sometimes take an effort to increase a market's transparency. For example, since the 2007-2008 financial crisis, financial regulators have imposed increasingly stringent transparency requirements for financial service providers. While the reasons for increasing transparency may lie outside the scope of

\footnotetext{
${ }^{1}$ See, e.g., Green and Porter (1984) for a formalization of the argument in a repeated-game model.

${ }^{2}$ Schenk-Hoppé (2000) and Huck et al. (2000) generalize and extend Vega-Redondo's (1997) model.

${ }^{3}$ See Potters (2009) for a review of laboratory experiments examining the effect of transparency on the competitiveness of markets.

${ }^{4}$ Information sharing could also dissolve demand or cost uncertainty, which could be beneficial for both firms and consumers. See Kühn and Vives (1995) for an overview of this literature.

5 Commission decision 87/1/EEC [1987] OJ L 3/17 (Case IV/31.128). See Kühn and Vives (1995) and Kühn (2001) for elaborate discussions of the case.
} 
competition between firms, they may have an effect on it, be it positive or negative.

In this paper, we take the position that the effect of publishing firm-specific data may depend on the opportunities for firms to collude explicitly. The publication of firmspecific data may result in two undesirable effects. First, it may increase cartel stability for the reasons put forward by Stigler (1964). Second, it may increase firms' incentives to form cartels, not only because it stabilizes cartels but also because the market may become more competitive otherwise as Vega-Redondo (1997) has pointed out. Existing experiments do not allow for identification of either effect. The reason is that in these experiments participants were not allowed to communicate so that explicit collusion was ruled out by construction. In other words, when participants wanted to collude, they could do so only tacitly. However, tacit collusion is rarely observed in the lab when oligopolies consist of three or four firms (Huck et al., 2004). The aim of our paper is to add to the debate by experimentally studying whether the effect of publishing firmspecific data on competition may depend on whether or not firms have the opportunity to form cartels.

In our experimental markets four identical firms chose quantities simultaneously for 50 periods. We exploit a two-treatment design. In the individualized information treatment, after each period, participants were informed about their own price and profits, the aggregate quantity of the market, and the quantities and profits of each of the other three firms. In the aggregate information treatment, participants only received information about their own price and profits and the aggregate quantity produced in the market. In both treatments, firms could not communicate for the first 25 periods. After that, a chat window was opened that enabled firms to communicate. Communication was optional, with no content or time restrictions, and possible every five periods.

We can summarize the results as follows. First, we found that communication helped to reach collusive agreements in both information scenarios. ${ }^{6}$ Market quantities dramatically decreased once firms could communicate, with most of the groups producing exactly the perfectly collusive quantity in both treatments. In addition, as in previous experimental studies, when communication was not allowed, quantities were significantly higher when individualized information was present. However, when communication was introduced, results reversed and quantities were lower with individualized information. Variations in cartel stability drive this result. When participants observed individualized information, members deviated less frequently from a collusive agreement than when only aggregate information was available.

\footnotetext{
${ }^{6}$ It is broadly documented in the literature that communication helps participants cooperate in oligopoly games and other dilemma games. See Crawford (1998) and Balliet (2010) for surveys of the literature. Recent experimental studies on the effectiveness of communication in oligopoly games include Andersson and Wengström (2007), Cooper and Kühn (2014), and Fonseca and Normann (2012, 2014). A different strand of the experimental literature deals with the question how players can credibly communicate private information (Dickhaut et al., 1995; Blume et al., 2001; Cai and Wang, 2006; Wang et al., 2010; De Groot Ruiz et al., 2014).
} 
To identify treatment effects regarding firms' incentives to form cartels, we follow Fonseca and Normann (2012) by measuring the gain from communication, i.e., the extra profits firms earn when communication is possible compared to the situation where communication is not allowed. We observe that the gain from communication is higher in the individualized information treatment than in the aggregate information treatment. This result suggests that publishing firm-specific data may encourage firms to form cartels because the benefits of doing so are higher when individualized information is available, while the costs (probability of detection/punishment) would be the same in both information scenarios.

The paper is organized as follows. The next section presents the experimental design and protocol. In Section 3, we discuss the theoretical predictions. Section 4 contains the experimental results. Section 5 concludes.

\section{Experimental design and protocol}

All sessions consisted of oligopoly market games where four identical firms, labeled $i=$ $1, \ldots, 4$, played a repeated differentiated Cournot game (fixed matching). Each firm $i$ was represented by a participant who had to choose the firm's quantity $q_{i}$ in each period. Marginal costs are constant and equal to $c>0$. Firm $i$ faced the following inversedemand function:

$$
P_{i}=\max \left\{a-q_{i}-\theta \sum_{j \neq i} q_{j}, 0\right\}, a>0, \theta \in[0,1),
$$

where $a$ and $\theta$ represent demand parameters that are constant across firms. Because $\theta \in[0,1)$, products are differentiated and therefore market prices need not be the same (firms may charge different prices for their products). We used the following parameters in the experiment: ${ }^{7}$

$$
a=150, \theta=\frac{2}{3}, \text { and } c=2 .
$$

We discuss the theoretical predictions in the next section.

All participants had full information about the demand and cost structure. In the instructions, formulas were provided. In addition, examples helped participants to understand how their own decisions and the quantities decided by the other firms affected the price at which they would sell the product. Moreover, they had access to an on-screen profit calculator in order to facilitate decision-making. The calculator gave the profits they would obtain under any combination of their own quantity and the total quantity produced by the other firms. The calculator was available at all times and the

\footnotetext{
7 Huck et al. (2000) use the same demand and cost structure in their experiment. Our demand is half theirs while the marginal costs are the same in the two experiments.
} 
participants could try as many quantity combinations as they wanted. In contrast to related experiments such as Huck et al. $(1999,2000)$, the calculator did not include a best-response button, because we feared that this would steer behavior.

We employed two information treatments, which varied in the information available to the participants about other firms' actions and outcomes. In both treatments, firms interacted for 50 periods in fixed groups. In each period, firms simultaneously chose their quantities from the set of integers between 0 and 200. In the aggregate information treatment (AGG), at the end of each period, participants were only informed about their own selling price, their own profits, and the aggregate quantity produced in the market in the current period. In the individualized information treatment (IND), in addition to the information revealed in AGG, firms were informed about the quantity decisions by each of the other three firms and their respective profits. As a way of illustration of how information was provided to the participants, figure A1 in Appendix A shows a screen shot for both treatments.

Communication possibilities are varied within-subjects. Both AGG and IND consisted of two parts of 25 periods each. In part 1, participants could not communicate while in part 2 they could communicate with the other firms in the same market using a chat window at the start of every five periods, i.e., in periods 26, 31, 36, 41, and 46. Firms had access to the profit calculator during the chat. During part 1, we did not inform the participants about the possibility to communicate in part 2. Our communication protocol closely follows Fonseca and Normann's (2012). There was no time limit and the content was unrestricted 8 for several reasons. First, cartels in real life usually arise from unrestricted communication among firms (the only restriction is that communication should be secret). In addition, restricting messages could have induced experimenter demand effects. Finally, previous literature has found that open communication is more effective in facilitating collusion in experimental markets than restricted communication. ${ }^{9}$ In our experiment, communication was costless and there was no risk to be discovered by an antitrust authority. This allows us to identify the benefits of communication, which, in turn, is informative about what information regime is more conducive to cartel formation in a setting where communication is costly. All chat content and all operations made in the profit calculator were recorded.

\footnotetext{
8 The usual restrictions were imposed: Participants were not allowed to use offensive language or to reveal their identity.

${ }^{9}$ Earlier experiments show that the set of messages that participants can use to communicate is quite crucial for sustaining collusion in laboratory markets. Cooper and Kühn (2014) find that collusion is persistent when rich communication between participants is possible, but not when only messages referring to cheating or punishing are allowed. The recent literature on the effectiveness of anti-cartel policy uses both non-restrictive communication (Apestaguia et al., 2006; Bigoni et al., 2014; Dijkstra et al., 2014) and restrictive communication (Hinloopen and Soetevent, 2008; Bigoni et al., 2012, 2015; Hinloopen and Onderstal, 2014).
} 
Table 1: Experimental design

\begin{tabular}{llll}
\hline Treatment & Information for firm $i$ & Part 1 (25 periods) & Part 2 (25 periods) \\
\hline AGG & $P_{i}, \sum_{j \neq i} q_{j}, q_{i}, \pi_{i}$ & No communication & Free communication \\
IND & $P_{i}, \sum_{j \neq i} q_{j},\left\{q_{j}, \pi_{j}\right\}_{j=1}^{4}$ & No communication & Free communication
\end{tabular}

Notes: $P_{j}\left(q_{j}\right)\left[\pi_{j}\right]$ represents firm $j$ 's price (quantity) [profits], $j=1, \ldots, 4$.

We did not include additional treatments where the parts of the experiment were reversed. Normann and Fonseca (2012), in a similar oligopoly market experiment, did not find order effects, i.e., the effect of communication for the competitiveness of oligopoly markets is the same when communication is preceded by periods of no communication than when this order is reversed. Table 1 summarizes the parts and treatments of the experiment. Both printed and computerized instructions are provided to the participants. A copy of the instructions for IND can be found in Appendix B. Before the experiment started, participants answered test questions to make sure that they understood the demand function they faced and the information at which they have access after each period. In addition, participants could try the profit calculator before the experiment started.

We ran eight computerized experimental sessions, four sessions for each treatment, at the CREED laboratory, University of Amsterdam. ${ }^{10}$ Participants were students from a variety of areas (approximately half of them having a background in Business or Economics). Depending on the number of participants that showed up, three to five groups (markets) of four people were formed in each session. In total, 18 markets were formed in AGG and 15 markets in IND. Each participant only participated in one of the sessions. Participants were randomly allocated to different computers so they could not infer which participants were in the same market. Sessions lasted between 75 and 100 minutes. Payment consisted of a show-up fee of 7 euros plus a payoff related to the total profits earned in the 50 periods. In particular, 5,000 experimental points were equivalent to 1 euro. Average earnings for participants, including the show-up fee, were 22.02 euros.

\section{Theoretical predictions}

In this section, three predictions for the experimental Cournot game are described: the one-shot Cournot-Nash equilibrium, the collusive benchmark, and the imitate-the-best benchmark.

10 The program was written using PHP and mySQL. 
The Cournot game has a unique one-shot Cournot-Nash equilibrium where all firms choose quantity

$$
q^{\text {COURNOT }}=\frac{a-c}{2+3 \theta}=37
$$

Choosing this quantity in each period is also a subgame perfect Nash equilibrium for the finitely repeated Cournot game. On the basis of the existing experimental literature on four-firm oligopoly games, ${ }^{11}$ we expect this outcome when communication among participants is not allowed and when a behavioral rule based on imitation is not possible (this is the case when individualized information is not presented to the individuals as in our treatment AGG).

Secondly, it is often observed in experiments that if the time horizon is long enough, participants may behave as if the time horizon is infinite. Therefore another possible theoretical benchmark prediction is a symmetric collusive outcome where firms maximize their joint profits. If participants in the lab perfectly collude, the individual quantity is: ${ }^{12}$

$$
q^{\text {COLLUSION }}=\frac{a-c}{2+6 \theta} \approx 25
$$

On the basis of the current literature on four-firm oligopoly games, this scenario is expected to arise only if firms can communicate. ${ }^{13}$ In addition, according to theory, the stability of collusive agreements does not depend on whether or not individualized information about other firms' quantities is revealed. In our setting, firms can perfectly deduce when another firm has deviated by observing the individual price or the total quantity produced by the other firms. So, in contrast to Stigler's (1964) and Green and Porter's (1984) setting, in our setting publishing individualized information should not affect cartel stability.

Finally, the last benchmark prediction is based on individuals using an imitation rule. If participants imitate the firm with the highest earnings (and make a mistake with a small probability by randomizing uniformly over the quantity space), the prediction for individual quantities is: ${ }^{14}$

$$
q^{\text {IMITATION }}=\frac{3(a-c)}{6+6 \theta} \approx 44 .
$$

Huck et al. (2000) show that the same outcome emerges in a Nash equilibrium if firms are assumed to maximize relative profits rather than absolute profits.

\footnotetext{
11 See Huck et al. (2004) for an overview of this literature.

${ }^{12}$ Quantities are rounded to the nearest integer; as in the experiment participants can only enter integer quantities.

13 See Fonseca and Normann (2012).

14 The proof of this result can be found in Huck et al. (2000).
} 
Note that the imitation benchmark predicts more competitive market outcomes than the Cournot-Nash equilibrium. As discussed in the introduction, the experimental literature suggests that the imitation benchmark is a good predictor in environments without communication where individualized information is provided, like in our IND treatment.

\section{Results}

This section reports the experimental results. Statistical analyses employ nonparametric two-sided Mann-Whitney and Wilcoxon tests with groups (18 in AGG and 15 in IND) as independent observations. Section 4.1 describes the differences in quantities produced between treatments and parts, i.e., how communication and the availability of firm-specific information affect the competitiveness of the experimental markets. Section 4.2 focuses on the stability of cartels formed when communication is possible. Section 4.3 examines the effect of presenting individualized data on the gain from communication.

\subsection{Quantities}

Figure 1 plots the evolution of average individual quantities per period and per treatment. In the first part of the experiment, quantities are higher in IND than in AGG. This difference increases over time, suggesting that participants tend to imitate the most successful firm, which is usually the firm producing the highest output. In order to test whether subjects indeed mimic the most successful firm in IND instead of best replying, we follow the method of Huck et al. (2000) and calculate "hit rates" that measure how close individual decisions are to the actions prescribed by the imitate-thebest behavioral rule and myopic best reply behavior. Specifically, the hit rate $h_{i}^{t}$ for individual $i$ in period $t$ is defined as $h_{i}^{t}=\frac{T_{i}^{t}-a_{i}^{t}}{T_{i}^{t}}$, where $T_{i}^{t}$ is the 'target', i.e., the prediction by a behavioral rule, and $a_{i}^{t}$ is the actual decision for individual $i$ in period $t$. Table 2 summarizes the results: $46 \%$ of the individual decisions are within the $10 \%$ neighborhood of the imitation target, while only $40 \%$ of the decisions lie in the $10 \%$ neighborhood of the best response to the previous period's quantities chosen by the competitors. In addition, the average hit rate using as target the imitation rule is 0.15 , while the hit rate using the best-response rule equals 0.22. Both differences are significant at the $5 \%$ level using two-sided Mann-Whitney U tests. 
Figure 1: Evolution of average individual quantities per treatment.

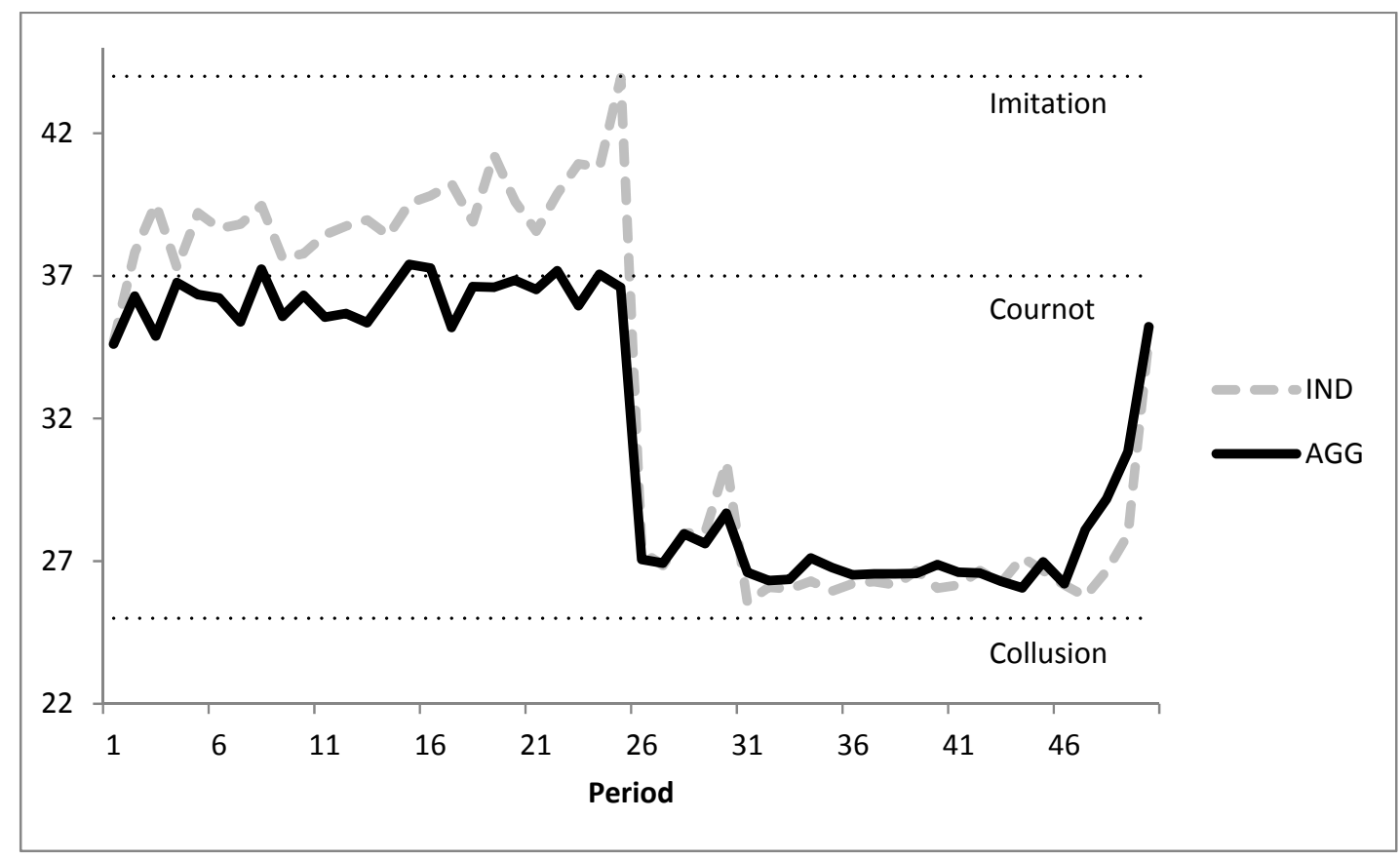

Table 2: Hit rates using Imitation and Best Reply as targets in the IND treatment.

\section{Target}

\begin{tabular}{lccc} 
& Imitation & & Best Reply \\
\hline Relative frequency of hits & $45.98 \%$ & & \\
within 10\% of target & $(15.47)$ & & $39.99 \%$ \\
& 0.15 & & $(20.14)$ \\
Average relative distance & $<*$ & 0.22 \\
to target & $(0.16)$ & & $(0.29)$
\end{tabular}

Notes: Standard deviations between brackets.

***/**/* Significant at the 1\%/5\%/10\% level (two-sided Mann-Whitney U test)

As of period 26, the first period in which firms can communicate, we observe a dramatic decrease in quantities produced in both treatments. In the following periods, average quantities are reasonably stable over time. Only in the first periods and in the last periods, quantities are somewhat higher. 
Table 3: Average individual quantities per treatment

\begin{tabular}{|c|c|c|c|c|c|c|}
\hline & \multicolumn{3}{|c|}{$\begin{array}{c}\text { Part 1: No } \\
\text { Communication }\end{array}$} & \multicolumn{3}{|c|}{ Part 2: Communication } \\
\hline & IND & & AGG & IND & & AGG \\
\hline All periods in that part & $\begin{array}{l}39.87 \\
(1.63)\end{array}$ & $>^{* * *}$ & $\begin{array}{l}36.23 \\
(1.92)\end{array}$ & $\begin{array}{l}27.05 \\
(3.76)\end{array}$ & $<*$ & $\begin{array}{l}27.59 \\
(2.60)\end{array}$ \\
\hline $\begin{array}{l}\text { Last } 20 \text { periods in that } \\
\text { part }\end{array}$ & $\begin{array}{l}39.52 \\
(1.76)\end{array}$ & $>* * *$ & $\begin{array}{l}36.35 \\
(1.72)\end{array}$ & $\begin{array}{l}26.78 \\
(4.25)\end{array}$ & $<*$ & $\begin{array}{l}27.35 \\
(2.87)\end{array}$ \\
\hline $\begin{array}{l}\text { Last } 15 \text { periods in that } \\
\text { part }\end{array}$ & $\begin{array}{l}40.40 \\
(1.87)\end{array}$ & $>^{* * *}$ & $\begin{array}{l}36.41 \\
(1.55)\end{array}$ & $\begin{array}{l}27.04 \\
(4.50)\end{array}$ & $<*$ & $\begin{array}{l}27.59 \\
(3.00)\end{array}$ \\
\hline
\end{tabular}

Notes: Standard deviations between brackets. Collusive, Cournot-Nash, and imitate-the-best quantities equal 25,37 , and 44 respectively.

*** $/ * * / *$ Significant at the $1 \% / 5 \% / 10 \%$ level (two-sided Mann-Whitney U test)

Table 3 shows average individual quantities produced in a market over all groups per treatment and per part. ${ }^{15}$ Averages are calculated for all periods, the last 20 and the last 15 periods to acknowledge possible learning effects. First, note that, when communication is not possible, the average individual quantity in AGG is close to the one-shot Nash-Cournot prediction. Moreover, the average quantity produced in IND is roughly midway between the Nash outcome and the imitate-the-best benchmark. More importantly, when communication is not possible, the average quantity produced is significantly higher in IND than in AGG $(p<0.001)$. This means that information about competitors' actions and profits makes markets more competitive when firms do not communicate. This is in line with the previous experimental literature. Moreover, when communication is not possible, firms do not manage to collude in either treatment: there is not a single period in the first part of the experiment where the total quantity produced by a group is close or equal to 100,16 the quantity that maximizes joint profits in the group. So, we can clearly reject the hypothesis that collusion is more stable when firms can monitor decisions of other firms in the same market when communication is not possible. When communication is possible, two important effects become apparent. First, the average quantity produced in the communication part is significantly lower than in the no-communication part for both treatments $(p<0.001$ for both AGG and IND). ${ }^{17}$ Non-restricted communication turns out to be quite helpful for participants to reach collusive agreements. Second, the difference in quantities produced among treatments is reversed: now IND is less competitive than AGG. This suggests that firm-

15 Tables C1 and C2 in the Appendix C present, for each group, average individual quantities over all periods in each of the treatments and in both parts of the experiment.

${ }^{16}$ The lowest total quantity produced in a group in a certain period of the no communication part was 122 , still far from the collusive total quantity, 100 (25 each firm).

17 Considering all periods, last 20 periods or last 15 periods 
specific data affects the competitiveness of oligopoly markets in a different direction when firms communicate. This difference is marginally statistically significant $(p=$ 0.09).

Summarizing, we find the following results:

Experimental result 1: The average quantity is significantly lower in the communication part than in the no-communication part for both treatments, meaning that communication helps to reach collusive agreements in both information scenarios.

Experimental result 2: If firms cannot communicate, the average quantity is significantly greater in IND than in AGG. In contrast, if firms can communicate, the average quantity is (weakly) significantly greater in AGG than in IND.

Figures 2 and 3 further illustrate this result. Each line in the graph represents the cumulative distribution function (cdf) of the average individual quantity produced in each treatment. Figure 2 refers to the first part of the experiment, where communication is not possible. The cdf of quantities in AGG first-order stochastically dominates the one in IND. Figure 3 refers to the second part of the experiment, when communication among firms in the same market is possible: now the cdf of IND firstorder stochastically dominates the cdf of AGG. Therefore, we can conclude that individualized information about competitors' actions and profits affects the competitiveness of oligopoly markets in opposite directions depending on whether firms communicate or not. Markets are more competitive when individualized information is available and communication is not possible, but become very anticompetitive when communication among firms is possible. In the next section this fact will be related to the stability of collusive agreements formed in the second part of the experiment.

Figure 3 suggests that the likelihood of perfect collusion depends on the information available to the firms in the same market. Collusion is defined to be 'successful' when the average individual quantity produced in a group lies in the interval $[24,26]$. Under this measure, $80 \%$ of the groups in IND are able to collude successfully during the second part of the experiment, compared to only $38.9 \%$ of the groups in AGG. The likelihood that a successful cartel emerges in the second part of the experiment is significantly higher in IND than in AGG $(p=0.019)$. We can state the third result as follows:

Experimental result 3: With communication successful cartels arise more often in IND than in $A G G$. 
Figure 2: Cumulative distributions of average individual production in the first, nocommunication part of the experiment

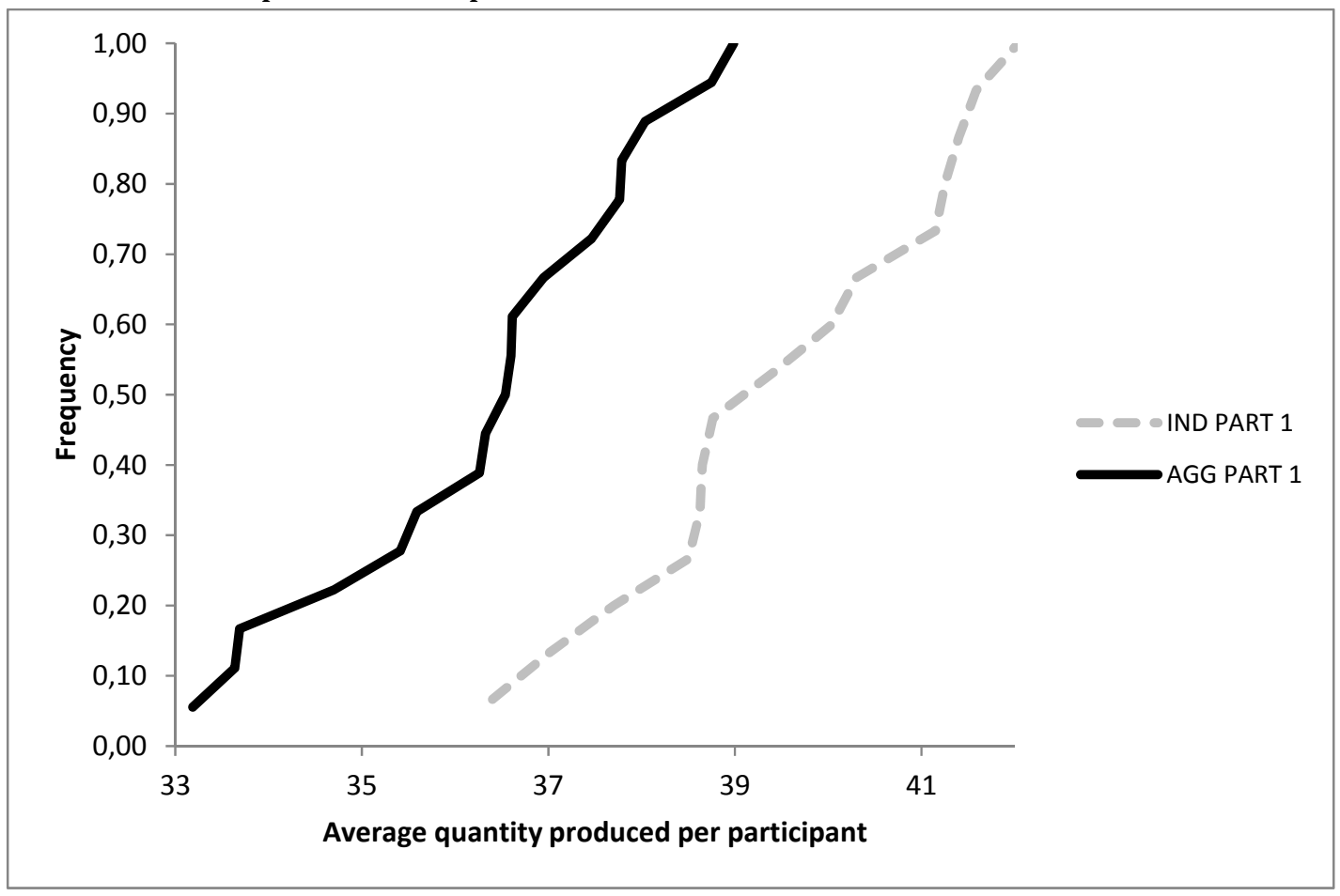

Figure 3: Cumulative distributions of average individual production in the second, communication part of the experiment

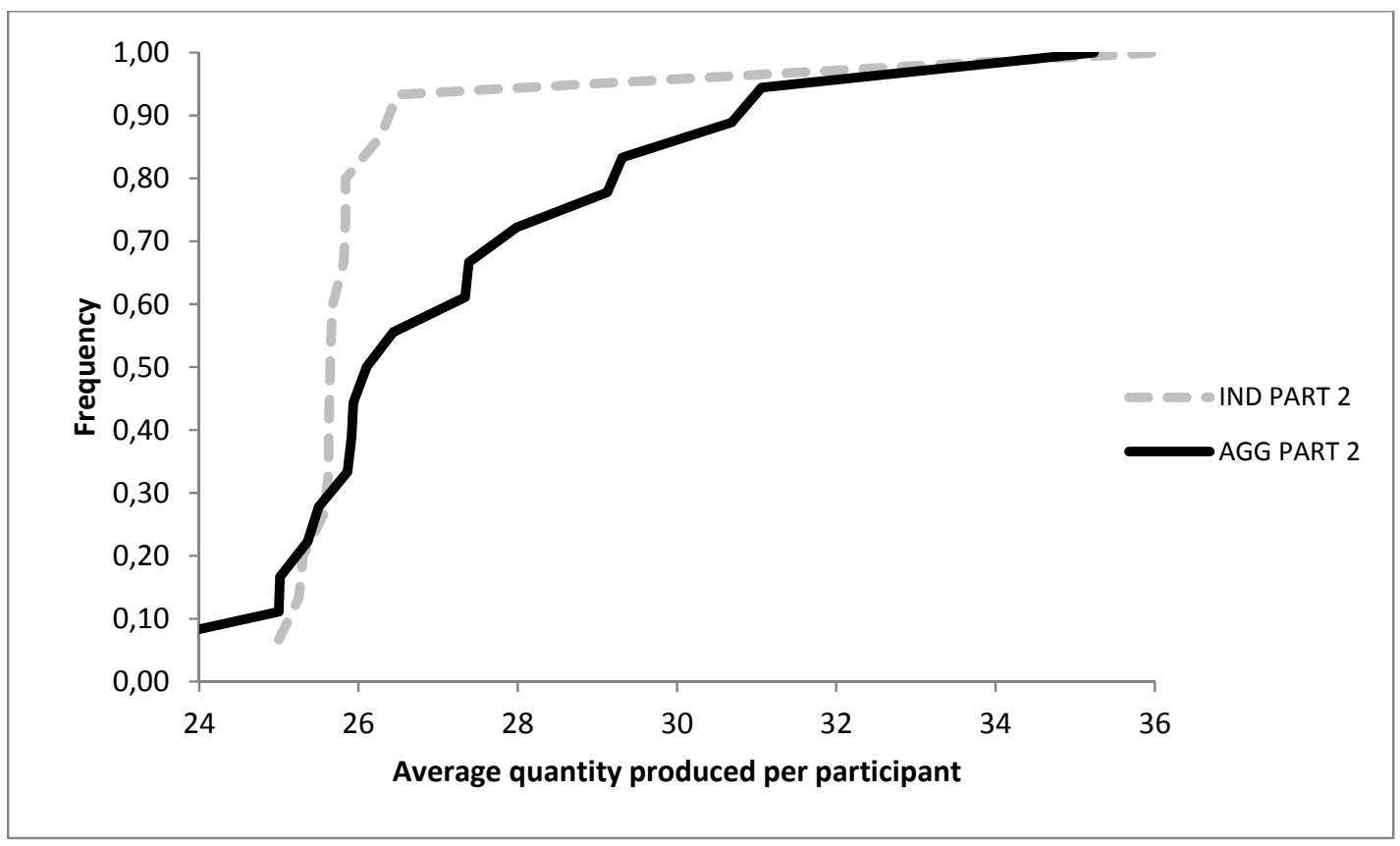


This important result suggests that cartels formed in IND are more stable than in AGG. Because the only difference between treatments is the availability of firm-specific data about competitors, this suggests that this kind of transparency in the market is making collusion more stable and therefore harming the competitiveness of the market. In the following section, the stability of cartels that arise in the second part of the experiment will be discussed.

\subsection{Cartel stability}

When communication among participants in the same group is not possible, participants do not manage to coordinate at producing the collusive quantity. There is not a single period in any of the groups where the average individual quantity is close to 25. This is in line with previous experimental literature in oligopoly markets that suggests that tacit collusion is very unlikely in experimental markets with four firms (Huck et al., 2004). On the other hand, during the communication part of the experiment, collusion emerged in most of the groups. The previous section showed that it is more likely that a successful cartel is formed in IND than in AGG. The current section examines the stability of cartels.

Figure C1 in Appendix C illustrates the difference in cartel stability between treatments. The figures represent the evolution of total production of each group for the periods 26 to 50 (when communication is possible every 5 periods). Remember there are 15 groups for IND and 18 groups for AGG. If we exclude the first and last 5 periods, 13 of the 15 groups in IND are able to form a perfect collusive agreement for all of the periods of the communication part (total quantity is equal to 100). In contrast, many of the groups in AGG show deviations from the perfect collusive outcome, meaning that they are not able to form as stable cartels as in IND.

More formally, cartel stability will be measured by the number of individual deviations after a cartel is explicitly formed. Therefore, we define cartels to be more stable when fewer deviations from the collusive agreement are found. A cartel is formed when at least one of these two events occur:

a) All participants in the same market explicitly agree in the chat to produce a certain quantity. Usually this happens as follows. Someone suggests a certain quantity that each firm should produce per period. Then participants discuss, and finally all explicitly agree about the quantity suggested.

b) All played a certain quantity discussed in the chat for at least 3 consecutive periods. It may be the case that one or more of the participants in the same group did not say explicitly "ok" or "I agree" in the chat but implicitly agreed with the strategy. If all the participants produce the quantity discussed in the chat for 3 or more consecutive periods, the cartel is considered to be formed. 
Table 4: Cartel stability per treatment

\begin{tabular}{lccc}
\hline & IND & AGG & $\begin{array}{c}p \text {-value 2-sided } \\
\text { Mann-Whitney test }\end{array}$ \\
\hline $\begin{array}{l}\text { Average number of } \\
\text { deviations per group }\end{array}$ & 3.20 & 5.36 & 0.06 \\
\hline
\end{tabular}

Notes: Standard deviations between brackets.

Table 4 shows the average number of individual deviations per group after a cartel is formed. The average number of deviations from the collusive agreement per group is higher in AGG than in IND. Tables C1 and C2 in Appendix C show the number of deviations for each of the groups in each of the treatments. ${ }^{18}$ The difference in individual deviations per group is significant. Therefore we state the following result: ${ }^{19}$

Experimental result 4: Collusion is more stable (less individual deviations from a cartel agreement) in markets where information about individual quantities and profits is present.

This result is in line with the results reported in the previous section about quantities. The correlations between the number of deviations and the average quantity produced are positive and very high $(R=0.9799 p$-value $=0.0000$ and $R=0.5189 p$-value $=0.0328$ for IND and AGG respectively). That we find more stable cartels in IND than in AGG is in line with the observation that markets are less competitive in IND than in AGG.

To conclude, cartels are more stable in IND than in AGG, explaining the difference in competitiveness found in previous section. This may be due to the fact that participants in IND are ashamed to cheat about the quantities agreed when other participants can monitor their individual decisions. This individual monitoring is not possible in AGG, allowing participants to hide behind the aggregate quantities and making competitors not able to distinguish who is the one cheating from the quantity agreed.

\subsection{Gain from communication}

It is clear from previous sections that communication helped firms to reach collusive agreements by reducing the total quantity produced in the market. This is reflected in the profits that firms earned in each part of the experiment. Firms' average profits increased by about $36 \%$ when communication was possible. Average individual profits

18 Only one of the experimental groups was not able to reach any kind of collusive agreement. Therefore this group is not included in the analysis of number of deviations.

${ }^{19}$ Alternative measures for cartel stability could be considered. For example, "the longest sequence of periods where the collusive quantity agreed was produced without a single deviation" could be used. In average, the perfectly collusive agreement lasts 18.73 consecutive periods in IND but only 14.27 periods in AGG. This difference is significant ( $p$-value $=0.0724$ ) 
during the first part of the experiment were 31,779 experimental points and in the second part 43,312 experimental points. In addition, participants clearly anticipated this fact. Almost all participants (126 of 132) that took part in the experiment decided to access to the first chat window and participate in the conversations. This suggests that participants anticipated the fact that communication among firms in the same market may have a positive impact on their profits. This positive influence of communication on profits earned by a firm is what Fonseca and Normann (2012) called "gain from communication". ${ }^{20}$ The gain from communication is a measure for the incentives for firms to start illegal conversations. This section compares the gain from communication in the two information scenarios.

Table 5 contains the average gain from communication per treatment, i.e. the average extra profits that a participant earns per period in the communication stage compared to the profits during the no communication stage. Table 5 shows that on average, the extra profits that a participant earns when communicating in IND is almost twice as large as the extra profits earned in AGG. This difference is statistically significant. Therefore we can state the fifth experimental result as follows:

Experimental Result 5: The gain from communication is higher in markets where information about individual quantity decisions and profits are available.

This result has important policy implications. Firms in markets where firm-specific data is accessible have stronger incentives to secretly talk and try to reach collusive agreements. This is because the potential gains of these talks are higher under this information scenario. Not only cartels would be more stable when individualized information is available, as shown in the last section, but firms (ex ante) know that potential collusive talks would have bigger benefits in that situation. As a consequence, publishing individualized information may encourage firms to talk in order to try to form cartels, because the benefits of doing so increase, but the costs (probability of detection or punishment by an antitrust authority) remain the same.

Table 5: Average gain from communication per period and per treatment.

\begin{tabular}{lccc}
\hline & & & $p$-value 2-sided \\
& IND & AGG & Mann-Whitney test \\
\hline Gain from communication & 612 & 360 & 0.001 \\
per period & $(245)$ & $(158)$ & \\
\hline
\end{tabular}

Notes: Standard deviations between brackets.

20 In a follow-up experiment, Fonseca and Normann (2014) confirm that cartels are more likely to form in four-firm oligopolies than in duopolies, consistent with the relative gain from communication in the two markets. 


\section{Conclusion}

The effect that firm-specific data have on the competitiveness of oligopoly markets is still an open debate in the economic literature. In our experiment, we compared markets where individualized data is available to participants (IND), with markets with only aggregate data (AGG). In the first part of the experiment communication among firms was not possible and, as in previous experiments, IND markets were more competitive than AGG markets. In the second part of the experiment unrestricted communication among participants in the same market was introduced. This reversed the results: IND markets were less competitive than AGG markets. In particular, collusive agreements were more stable in the individualized treatment. The driving force may be that participants felt a stronger fear to be caught cheating and punished when other participants could monitor their individual decisions. However, also in the aggregate-data treatment, other participants could find out that someone cheated because the aggregate quantity would increase so it is not clear why in this treatment, participant were more likely to deviate. Further research is needed to find the actual mechanism through which individualized information makes cartels more stable. We also showed that the gain from communication is higher in the individualized treatment compared to the aggregate treatment.

Summarizing, our results point to a perverse effect of publishing firm-specific data in the sense that more public information could both stabilize cartels and encourage cartel formation. Our observations are consistent with Potters' (2009) conjecture that "[i]nformation exchange is more likely to be a consequence of explicit collusion than to be a cause of implicit collusion". As a consequence, our findings support the European Commission's decision in the Fatty Acids case to declare the individual information exchange between Unilever, Henkel, and Oleofina illegal In other words, information exchange about firm-specific outputs and profits should be discouraged (if not declared illegal in view of competition law), in markets where explicit collusive behavior is likely to occur.

Moreover, our results indicate that regulators should be careful when increasing market transparency because this could fuel cartel formation. For example, financial regulators should keep in mind that more stringent transparency requirements for financial service providers might increase cartel formation in the market as an undesirable byproduct. If regulators do not want to harm competition, they should only boost transparency in financial markets that are not very concentrated, where cartel formation is unlikely.

\section{References:}

Albaek, S., Møllgaard, P., \& Overgaard, P. B. (1997). Government-assisted oligopoly coordination? A concrete case. The Journal of Industrial Economics, 45(4), 429-443. 
Altavilla, C., Luini, L., \& Sbriglia, P. (2006). Social learning in market games. Journal of Economic Behavior \& Organization, 61(4), 632-652.

Andersson, 0., \& Wengström, E. (2007). Do antitrust laws facilitate collusion? Experimental evidence on costly communication in duopolies. The Scandinavian Journal of Economics, 109(2), 321-339.

Apesteguia, J., Dufwenberg, M., \& Selten, R. (2007). Blowing the whistle. Economic Theory, 31(1), 143-166.

Balliet, D. (2010). Communication and cooperation in social dilemmas: A meta-analytic review. Journal of Conflict Resolution, 54(1), 39-57.

Bigoni, M., Fridolfsson, S. O., Le Coq, C., \& Spagnolo, G. (2012). Fines, leniency, and rewards in antitrust. The RAND Journal of Economics, 43(2), 368-390.

Bigoni, M., Fridolfsson, S. O., Le Coq, C., \& Spagnolo, G. (2015). Trust, salience and deterrence: Evidence from an antitrust experiment. Journal of Law, Economics and Organization, forthcoming.

Bigoni, M., Potters, J., \& Spagnolo, G. (2014). Flexibility and cooperation with imperfect monitoring. Working paper, Tilburg University.

Blume, A., DeJong, D. V., Kim, Y.-G., \& Sprinkle, G. B. (2001). Evolution of communication with partial common interest. Games and Economic Behavior, 37, 79-120.

Cai, H., \& Wang, J. T. (2006). Overcommunication in strategic information transmission games. Games and Economic Behavior, 56, 7-36.

Cooper, D. J., \& Kühn, K.-U. (2014). Communication, Renegotiation, and the Scope for Collusion. American Economic Journal: Microeconomics, 6(2), 247-278.

Crawford, V. (1998). A survey of experiments on communication via cheap talk. Journal of Economic Theory, 78(2), 286-298.

De Groot Ruiz, A., Offerman, T., \& Onderstal, S. (2014). For those about to talk we salute you: an experimental study of credible deviations and ACDC. Experimental Economics, 17(2), 173-199.

Dickhaut, J. W., McCabe, K. A., \& Mukherji, A. (1995). An experimental study of strategic information transmission. Economic Theory, 6, 389-403.

Dijkstra, P.T., Haan, M.A., \& Schoonbeek, L. (2014) Leniency programs and the design of antitrust: Experimental evidence with rich communication. Working paper, University of Groningen

Fonseca, M. A., \& Normann, H. T. (2012). Explicit vs. tacit collusion-The impact of communication in oligopoly experiments. European Economic Review, 56(8), 1759-1772.

Fonseca, M. A., \& Normann, H. T. (2014). Endogenous cartel formation: Experimental evidence. Economics Letters, 125(2), 223-225.

Green, E. J., \& Porter, R. H. (1984). Noncooperative collusion under imperfect price information. Econometrica, 52(1), 87-100.

Hinloopen, J., \& Soetevent, A. R. (2008). Laboratory evidence on the effectiveness of corporate leniency programs. The RAND Journal of Economics, 39(2), 607-616.

Hinloopen, J., \& Onderstal, S. (2014). Going once, going twice, reported! Cartel activity and the effectiveness of antitrust policies in experimental auctions. European Economic Review, 70, 317-336.

Huck, S., Normann, H. T., \& Oechssler, J. (1999). Learning in Cournot oligopoly-An experiment. The Economic Journal, 109(454), 80-95.

Huck, S., Normann, H. T., \& Oechssler, J. (2000). Does information about competitors' actions increase or decrease competition in experimental oligopoly markets?. International Journal of Industrial Organization, 18(1), 39-57.

Huck, S., Normann, H. T., \& Oechssler, J. (2004). Two are few and four are many: number effects in experimental oligopolies. Journal of Economic Behavior \& Organization, 53(4), 435446.

Kühn, K. U. (2001). Fighting collusion by regulating communication between firms. Economic Policy, 16(32), 168-204. 
Kühn, K. U., \& Vives, X. (1995). Information exchange among firms and their impact on competition. European Commission paper.

Offerman, T., Potters, J., \& Sonnemans, J. (2002). Imitation and belief learning in an oligopoly experiment. The Review of Economic Studies, 69(4), 973-997.

Potters, J. (2009). Transparency about past, present and future conduct. Experimental evidence on the impact on competitiveness. In J. Hinloopen and H.-T. Normann (eds.), Experiments and Competition Policy. Cambridge: Cambridge University Press.

Schenk-Hoppé, K. R. (2000). The evolution of Walrasian behavior in oligopolies. Journal of Mathematical Economics, 33(1), 35-55.

Stigler, G. J. (1964). A theory of oligopoly. The Journal of Political Economy, 72(1), 44-61.

Vega-Redondo, F. (1997). The evolution of Walrasian behavior. Econometrica, 65(2), 375-384.

Wang, J. T., Spezio, M., \& Camerer, C. F. (2010). Pinocchio's pupil: using eyetracking and pupil dilation to understand truth telling and deception in sender-receiver games. The American Economic Review, 100, 984-1007. 


\section{APPENDIX A:}

Figure A1:

AGG

Period 2

You are frm A and your accumulated profits are 3025 port?

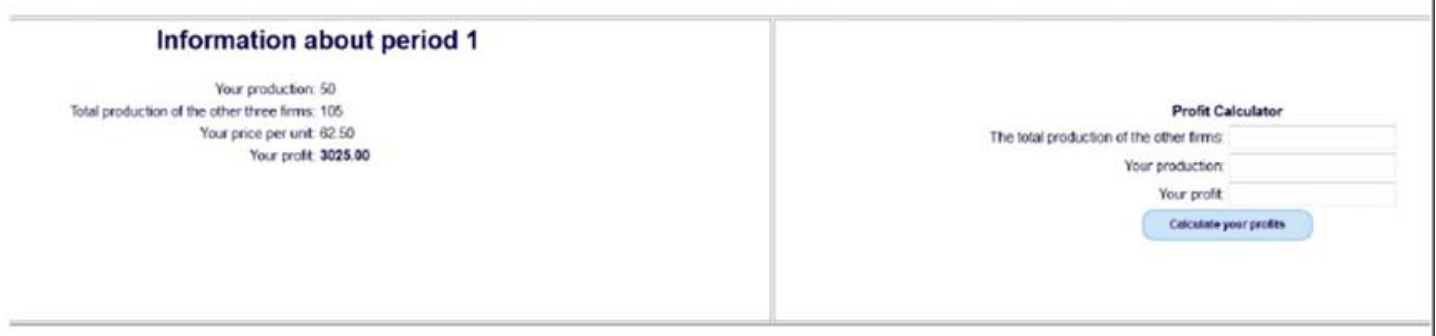

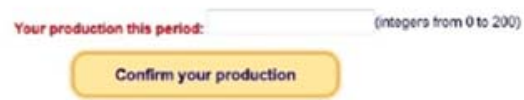

IND

Period 2

You are $\mathrm{fmm}$ A and your accumvilsed profits are 3025 poirts

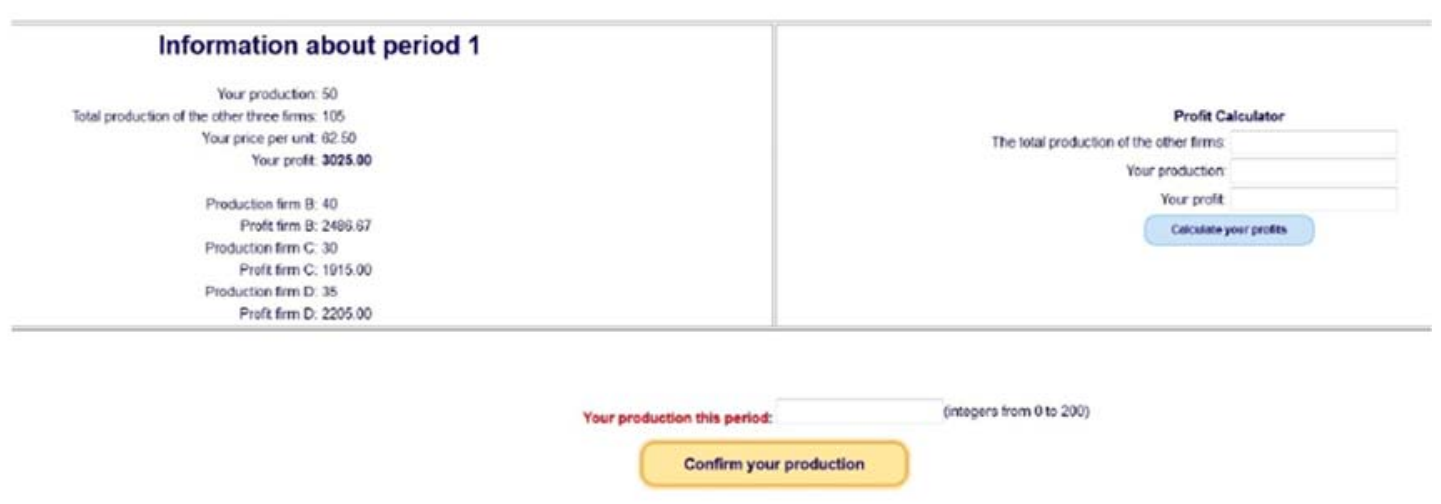




\section{Appendix B}

\section{Instructions}

The experiment consists of two parts. Part 2 will be explained after we have finished part 1.

The instructions are simple, and if you follow them carefully, you might earn a considerable amount of money. What you earn depends on the decisions you make and on the decisions of the others. You will be privately paid at the end of the experiment.

We ask that you do not communicate with other people during the experiment. Please refrain from verbally reacting to events that occur during the experiment. This is very important.

Raise your hand when you have a question and one of the experimenters will come to your table.

\section{Part 1}

In this experiment you represent a firm. The profits that your firm obtains during the experiment determine the money that you will receive. In particular, each 5000 points that your firm earns will correspond to 1 euro for your pocket. In addition, you will receive a showup fee of 7 euros, independent of your performance in the experiment.

There are in total 4 firms in the same market, with the codes A, B, C and D. The other firms are represented by 3 other participants in the experiment. You will interact with the same 3 other participants throught the whole experiment, but you will never know their identity.

Part 1 consists of 25 periods. In every period you have to decide the quantity that your firm produces.

The cost of producing a unit of that good is 2 points. Your profit will depend on the number of units you decide to produce and on the price at which they are sold. It is important to notice that the higher the quantity that firms decide to sell, the lower the price they will get per unit. In particular, the price is given by the following formula :

$$
P_{\text {you }}=150-q_{\text {you }}-\frac{2}{3} Q_{\text {others }}
$$

where $\mathbf{P}_{\text {you }}$ is the price at which you sell your product and $\mathbf{q}_{\mathbf{y o u}}$ is the quantity you have decided to sell. $\mathbf{Q}_{\text {others }}$ is the sum of the quantities that the other $\mathbf{3}$ firms have decided to produce. The price can never be lower than 0 . The price of the other firms is determined in the same way.

You can interpret this formula as follows. If you decide to increase your quantity by 10 units, your price will be also decrease by 10 points, but the price of the others will decrease only by $10 * 2 / 3=6.67$ points.

It is also important to notice that there is not a unique market price. In other words, the price at which each firm sells the product can be slightly different. This is actually true in real world. Firms charge different prices for their brands even though their products are similar. 
Summarizing, the price will depend on the total production of all firms. More production implies more units sold but at a lower price. Less production implies fewer units sold but at a higher price.

The profits of your firm are the difference between the revenues you get from selling the units produced and the cost of producing these units:

$$
\text { Profits }_{\text {you }}=P_{\text {you }} \cdot q_{\text {you }}-2 q_{\text {you }}
$$

\section{EXAMPLE 1}

If you decide to produce 10 units, and each of the other 3 firms produces 15 units, the price at which you will sell the product will be: $P=150-10-2 / 3^{*}(45)=110$. Your profits will be :

Profits $=110 * 10-2 * 10=1080$

\section{EXAMPLE 2}

If you decide to produce $\mathbf{4 0}$ units, and each of the other 3 firms produces $\mathbf{3 0}$ units, the price at which you will sell the product will be: $\mathbf{P}=\mathbf{1 5 0}-\mathbf{4 0}-\mathbf{2} / \mathbf{3}^{*}(\mathbf{9 0})=\mathbf{5 0}$. Your profits will be :

Profits $=50 * 40-2 * 40=1920$

\section{EXAMPLE 3}

If you decide to produce $\mathbf{8 0}$ units, and each of the other 3 firms make the same decision, the price will be 0 . All firms will make a loss of 160.

During the experiment you will not need to make calculations by hand. In order to make your decisions easier, we will provide you with an on-screen profit calculator that will help you to choose the quantity produced every period. In this calculator you can introduce arbitrary quantities and it will calculate your profits. That is, you introduce your own quantity and the total quantity of the other 3 firms, and the calculator will give you your profits for this quantity combinations. You will have the opportunity to try the calculator before the experiment starts.

\section{Information}

Finally, after each period, when all firms in your market have made a decision, you will obtain some information before going to the next period. In particular you will be told:

- The price at which you sold the product.

- Your profits.

- The total quantity produced by the other 3 firms.

- The individual quantities produced by the 3 other firms.

- The (individual) profits for each of the 3 other firms.

Important notice : All firms in your market are exactly the same and all participants are reading the same instructions as you.

\section{Profit Calculator}

The use of the profit calculator is very simple. 
1. You enter the total quantity that you think the other firms will produce (the sum of the units produced by the other 3 firms).

2. You enter the quantity that you consider best to produce.

3. You click on the button "Calculate" and the calculator will show the profits you will obtain if these quantities will indeed be produced.

\section{Profit Calculator}

The total production of the other firms:

Your production:

Your profit:

\section{Calculate your profits}




\section{APPENDIX C:}

Table C1: IND. TREATMENT by group

\begin{tabular}{|l|c|c|c|c|c|}
\hline $\begin{array}{c}\text { Average } \\
\text { individual } \\
\text { quantity }\end{array}$ & $\begin{array}{c}\text { Average } \\
\text { individual } \\
\text { quantity } \\
\text { (No }\end{array}$ & $\begin{array}{c}\text { Average } \\
\text { individual } \\
\text { quantity } \\
\text { communication) }\end{array}$ & $\begin{array}{c}\text { Number } \\
\text { of } \\
\text { individual } \\
\text { deviations }\end{array}$ & $\begin{array}{c}\text { Longest } \\
\text { sequence } \\
\text { of } \\
\text { periods } \\
\text { without } \\
\text { deviation }\end{array}$ & $\begin{array}{c}\text { Gain from } \\
\text { communication } \\
\text { per period }\end{array}$ \\
\hline Group IND.1 & 37.81 & 25.45 & 2 & 22 & 585 \\
\hline Group IND.2 & 36.52 & 25.51 & 1 & 24 & 406 \\
\hline Group IND.3 & 41.00 & 40.07 & 22 & 0 & -94 \\
\hline Group IND.4 & 36.90 & 25.57 & 5 & 14 & 455 \\
\hline Group IND.5 & 37.82 & 25.54 & 2 & 20 & 594 \\
\hline Group IND.6 & 39.48 & 25.66 & 3 & 14 & 735 \\
\hline Group IND.7 & 40.71 & 27.99 & 1 & 19 & 839 \\
\hline Group IND.8 & 39.74 & 25.00 & 0 & 25 & 668 \\
\hline Group IND.9 & 37.47 & 26.72 & 2 & 18 & 488 \\
\hline Group IND.10 & 39.62 & 26.27 & 3 & 17 & 712 \\
\hline Group IND.11 & 40.47 & 25.24 & 1 & 24 & 786 \\
\hline Group IND.12 & 41.95 & 25.50 & 2 & 23 & 947 \\
\hline Group IND.13 & 40.49 & 28.04 & 1 & 19 & 816 \\
\hline Group IND.14 & 38.21 & 25.20 & 1 & 24 & 640 \\
\hline Group IND.15 & 39.23 & 27.97 & 2 & 18 & 606 \\
\hline
\end{tabular}

Table C2: AGG. TREATMENT by group

\begin{tabular}{|l|c|c|c|c|c|}
\hline \multicolumn{1}{|c|}{ IND. } & $\begin{array}{c}\text { Average } \\
\text { individual } \\
\text { quantity } \\
\text { (No }\end{array}$ & $\begin{array}{c}\text { Average } \\
\text { individual } \\
\text { quantity } \\
\text { communication) }\end{array}$ & $\begin{array}{c}\text { Number } \\
\text { of } \\
\text { individual } \\
\text { deviations }\end{array}$ & $\begin{array}{c}\text { Longest } \\
\text { sequence } \\
\text { of } \\
\text { periods } \\
\text { without } \\
\text { deviation }\end{array}$ & $\begin{array}{c}\text { Gain from } \\
\text { communication } \\
\text { per period }\end{array}$ \\
\hline Group AGG.1 & 32.37 & 31.71 & 4 & 16 & 138 \\
\hline Group AGG.2 & 35.45 & 33.79 & NA $^{21}$ & NA & 85 \\
\hline Group AGG.3 & 38.43 & 25.52 & 1 & 19 & 210 \\
\hline Group AGG.4 & 34.20 & 25.44 & 2 & 19 & 325 \\
\hline Group AGG.5 & 34.48 & 27.89 & 10 & 7 & 287 \\
\hline Group AGG.6 & 35.92 & 25.88 & 3 & 22 & 382 \\
\hline Group AGG.7 & 36.70 & 27.01 & 7 & 12 & 382 \\
\hline Group AGG.8 & 35.32 & 28.45 & 15 & 7 & 252 \\
\hline Group AGG.9 & 37.19 & 25.67 & 3 & 19 & 403 \\
\hline Group AGG.10 & 33.70 & 27.17 & 8 & 9 & 222 \\
\hline Group AGG.11 & 35.20 & 30.84 & 2 & 18 & 264 \\
\hline Group AGG.12 & 37.63 & 25.01 & 1 & 22 & 569 \\
\hline Group AGG.13 & 38.87 & 25.69 & 2 & 23 & 629 \\
\hline Group AGG.14 & 36.74 & 25.00 & 0 & 25 & 435 \\
\hline Group AGG.15 & 40.18 & 25.9 & 4 & 18 & 651 \\
\hline Group AGG.16 & 36.19 & 26.16 & 6 & 5 & 364 \\
\hline Group AGG.17 & 36.53 & 30.37 & 21 & 4 & 362 \\
\hline Group AGG.18 & 37.14 & 25.75 & 2 & 12 & 512 \\
\hline
\end{tabular}

${ }^{21}$ Only one of the experimental groups was not able to reach any kind of collusive agreement. Therefore this group is not included in the analysis of number of deviations. 
Figure C1: Evolution of total quantity produced by each group in part 2 of the experiment.22

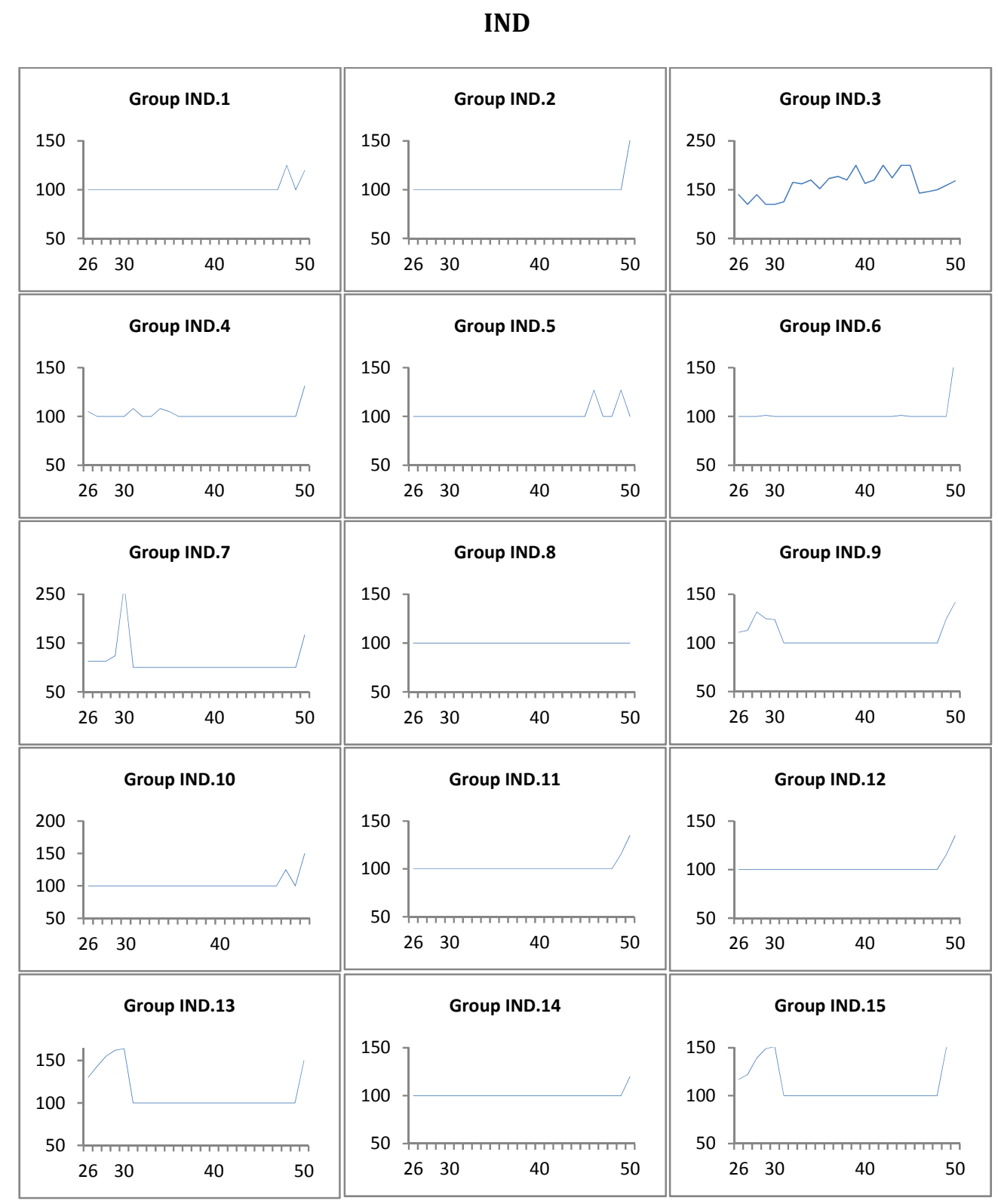

${ }^{22}$ The scale of vertical axes is expanded in Group IND.3 and IND.7. 


\section{AGG}

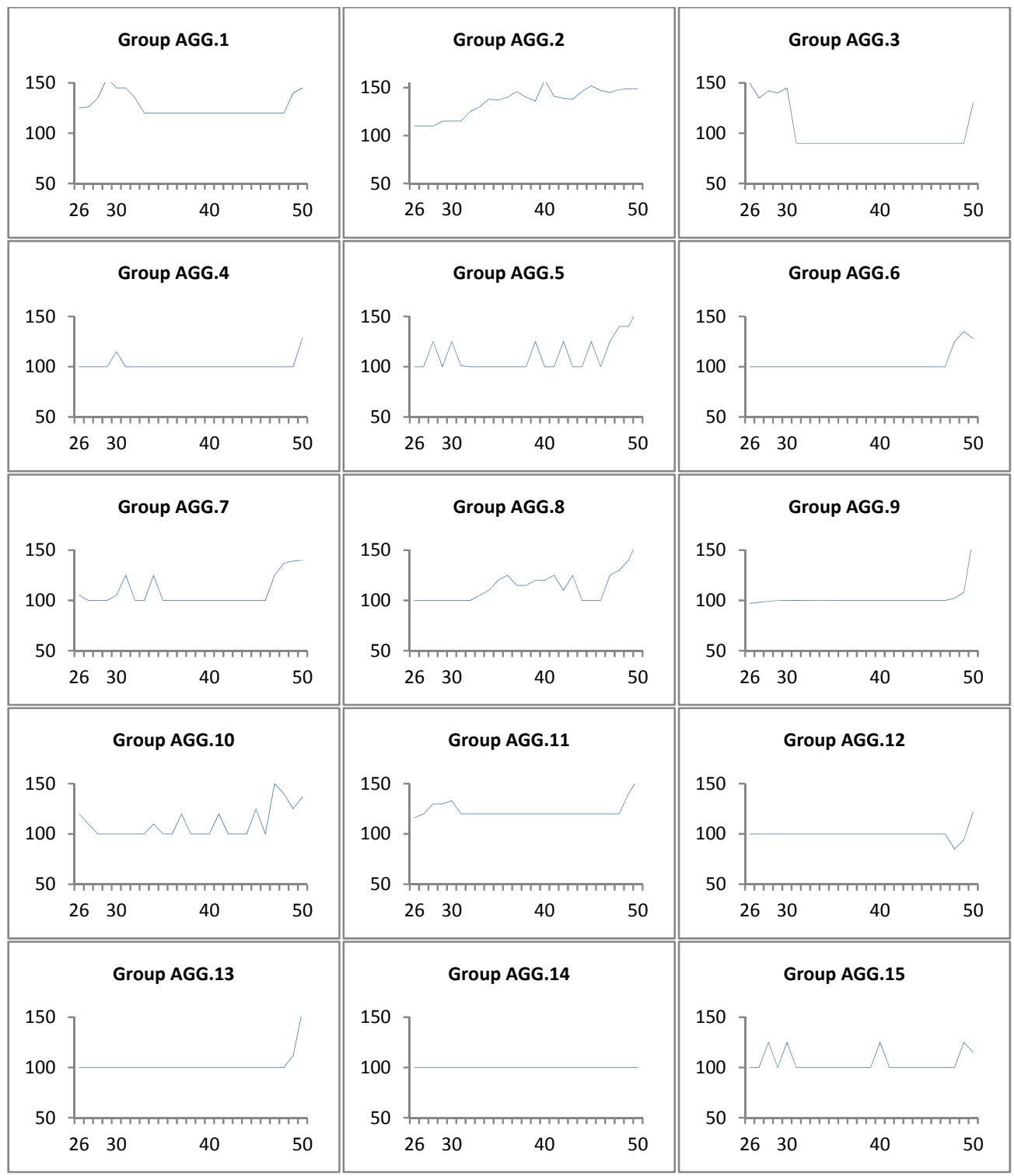

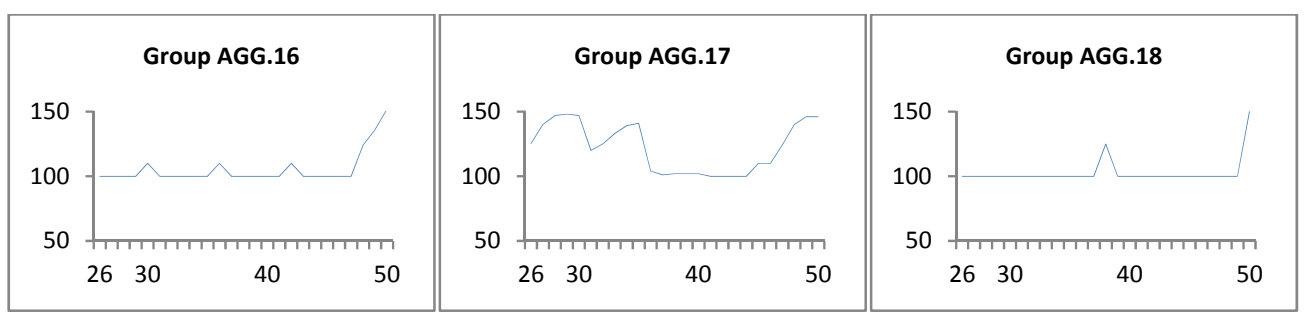

